\title{
Remarkable Solar Cycle and Seasonal Dependence of the Diurnal Geomagnetic $D$-Variations at Equatorial Electrojet Station, Kodaikanal
}

\author{
R. G. RASTOGI \\ CSIR Emeritus Scientist, Physical Research Laboratory, Ahmedabad 380 009, India
}

(Received January 11, 1993; Revised May 26, 1993)

\begin{abstract}
Concurrent with the midday maximum of horizontal geomagnetic field, $H$, the eastward field $Y$ at the equatorial electrojet station Kodaikanal shows a distinct minimum around noon during any of the years of solar cycle. The sunspot cycle variations of the daily variations of $\Delta Y$ are sympathetical with those of $\Delta H$. Even the day to day fluctuations of the daily range $Y$ are correlated with corresponding changes of $H$. Abnormal seasonal changes are seen in the daily variations of $Y$ field at Kodaikanal as well as at other observations in India. These significant daily variations of eastward field at Kodaikanal are suggested to be due to a systematic meridional current associated with the electrojet current
\end{abstract}

\section{Introduction}

The geomagnetic observatory at Kodaikanal (geog lat. $10.2^{\circ} \mathrm{N}$; geog long. $77.5^{\circ}$; dip $3.4^{\circ} \mathrm{N}$ ) has provided very important set of data which when compared with the data from Huancayo had assisted EGEDAL (1947) to discover the equatorial electrojet current itself. Numerous studies have been made of the data from this observatory for the various phenomena like equatorial normal as well as counter electrojet currents on geomagnetically quiet as well as disturbed days. However, the most widely used data has been the horizontal component, $H$, and to a lesser extent the vertical component, $Z$, both closely associated with the ribbon structure of the equatorial electrojet currents. Recently, RASTOGI (1993b) found abnormally low values of the electrojet current and proportionately large number of days with westward current during the month of December 1975. The abnormal features of the equatorial electrojet during December solstices were shown to be associated with the disappearance of the loop type $S q$ current system in Indian longitude zone (RASTOGI, 1993a). Since 1975, there exists an excellent chain of nine geomagnetic observatories along a narrow longitude sector of India starting from the dip equator upto the latitude close to the $S q$ focus. ARORA et al. (1980) have used the data from all these observatories in India to isolate the solar and lunar tidal components. The diagram showing the average $S q(D)$ variations indicated abnormally small and reversed variations during the winter (December) months. PATIL et al. (1983) combined the data from these Indian observatories with the data from former USSR observatories to study the $S q$ and equatorial electrojet currents along $75^{\circ} \mathrm{E}$ longitude sector. It was shown that the eastward component of the geomagnetic field, $Y$, at all stations showed significant variation during the daytime. The variation of $Y$ showed a single minimum around noon at equatorial stations while at stations outside the electrojet belt $\Delta Y$ was maximum during forenoon and minimum during afternoon hours. The daily variations of declination (or $Y$ ) at stations in the American sector showed a more complex variation during the daytime hours and has been explained due to the latitudinal shift of the boundary of northern and southern loops of the $S q$ current system with the time of the day (HUTTON, 1967).

Some studies of the daily variations of the declination have been made by PRICE and STONE (1964), GUPTA (1973) and others. However, no abnormality associated with equatorial electrojet region has been identified. Recently, FUKUSHIMA (1992) has stated "In the future studies of the equatorial electrojet and the geomagnetic $S q$ field in middle and low latitudes, more attention should be generally paid to the importance of the daily and seasonal changes in the magnetic declination". 


\section{Analysis}

In view of rather little literature on the concurrent time variations of $H, D$ and $Z$ components at equatorial regions, the data of geomagnetic field at Kodaikanal have been analysed for the components of solar daily variations and the results are described here. The period of data covered 1954 to 1968, a complete solar cycle with a peak solar activity with yearly average number around 200 during 1957-58.

First, the yearly mean solar daily variations of $H, Y$ and $Z$ components were computed for each of the years and are shown in Fig. 1 together with the annual mean sunspot number. The $H$ field during any of the years showed a maximum shortly before noon and the daily range varied sympathetically with the changes in sunspot number. During low sunspot number the $H$ field was above the night time base level only between 06 and $16 \mathrm{hr}$ but during the high sunspot years the field after reaching the midday peak, decreased very slowly until the midnight hours. These features have been discussed by RASTOGI and PATIL (1992). Kodaikanal, being situated slightly away from the centre of the equatorial electrojet (dip latitude $1.6^{\circ} \mathrm{N}$ ), the daily variation of the vertical component $(Z)$ is comparatively larger than at other low latitude stations and a midday minimum was observed during any of the years.

It was interesting to find that the Eastward field, $Y$, also showed regular midday minimum during any of the years. It seems that in the Indian longitude sector the daily variations of $H, Y$ and $Z$ at equatorial latitudes are some way associated with the equatorial electrojet phenomenon.

It is clear from Fig. 1 that the midday values of $\Delta H, \Delta Z$ or $\Delta Y$ is closely related with the sunspot number. To ascertain this features the midday values of $\Delta H, \Delta Z$ and $\Delta Y$ at Kodaikanal for the period 1954 1968 are plotted against yearly mean sunspot number $R$ in Fig. 2. The daily range of $H, Z$ and $D$ are found to be related linearly to sunspot number. Fitting an equation

$$
\Delta(H, Z, Y)=\Delta(H, Z, Y)_{0} \times(1+b R)
$$

it is seen that the value of $b$ is 0.006 for $\Delta H$ and 0.005 for $\Delta Z$ and $\Delta Y$. The zero sunspot value is $60.1 \mathrm{nT}$ for $\Delta H,-14.7 \mathrm{nT}$ for $\Delta Z$ and $-17.6 \mathrm{nT}$ for $\Delta Y$. Thus the ratio of daily ranges at $R_{100}$ and $R_{0}$ are 1.6 for $\Delta H$ and about 1.5 for $\Delta Z$ and $\Delta Y$. This again gives direct association in the daily variation of $H, Z$ and $Y$ at Kodaikanal.

Next, these yearly average daily variation curves of $H, Y$ and $Z$ were subjected to Fourier analysis to yield the amplitudes of diurnal components as well as the local times when these components reached the maximum or the minimum excursions. In Fig. 3 are shown year to year variations of the amplitude $\left(C_{1}\right.$, $\left.C_{2}\right)$ and phase $\left(T_{1}\right.$ or $\left.T_{2}\right)$ of these harmonic components of $H, Y$ and $Z$ for the period 1954-68. The yearly mean sunspot numbers during this period are also shown for comparison.

It is seen that in the case of horizontal and vertical fields the diurnal $\left(C_{1}\right)$ component predominates over the semi-diurnal $\left(C_{2}\right)$ one, the ratio $C_{1} / C_{2}$ being about two. In the case of eastward field, the $C_{1}$ and $C_{2}$ components are almost same during any of the years under study. The amplitude $C_{1}$ and $C_{2}$ for any of the fields $H, Z$ and $Y$ follow the progress of sunspot number.

The local times $T_{1}(\max )$ and $T_{2}(\max )$ when the diurnal and semi-diurnal components respectively of $H$ field reaches the maximum value follow the solar cycle. During the low sunspot years $T_{1}(\max ) H$ and $T_{2}(\max ) H$ are roughly the same giving a daily variation symmetrical around $1100 \mathrm{LT}$. During the high sunspot years $T_{2}(\max ) H$ is advanced by about $1 / 2$ hour and $T_{1}(\max ) H$ by about 1.0 hour and the daily variation of $H$ gets asymmetric about noon. This is in confirmation with the results of RASTOGI and IYER (1976) for the daily variation of $H$ field at low latitudes.

The times of minimum vertical field $T_{1}(\mathrm{~min}) Z$ and $T_{2}(\mathrm{~min}) Z$ follow the sunspots fairly well. $T_{2}(\mathrm{~min})$ $Z$ is around $1200 \mathrm{LT}$ during low and $1300 \mathrm{LT}$ during high sunspot years. $T_{1}(\mathrm{~min}) Z$ is roughly advanced by one hour with respect to $T_{2}(\min ) Z$ during any of the years.

The times $T_{1}(\mathrm{~min}) Y$ and $T_{2}(\mathrm{~min}) Y$ also follow the solar cycle, $T_{1}(\mathrm{~min}) Y$ was around $1200 \mathrm{LT}$ during 


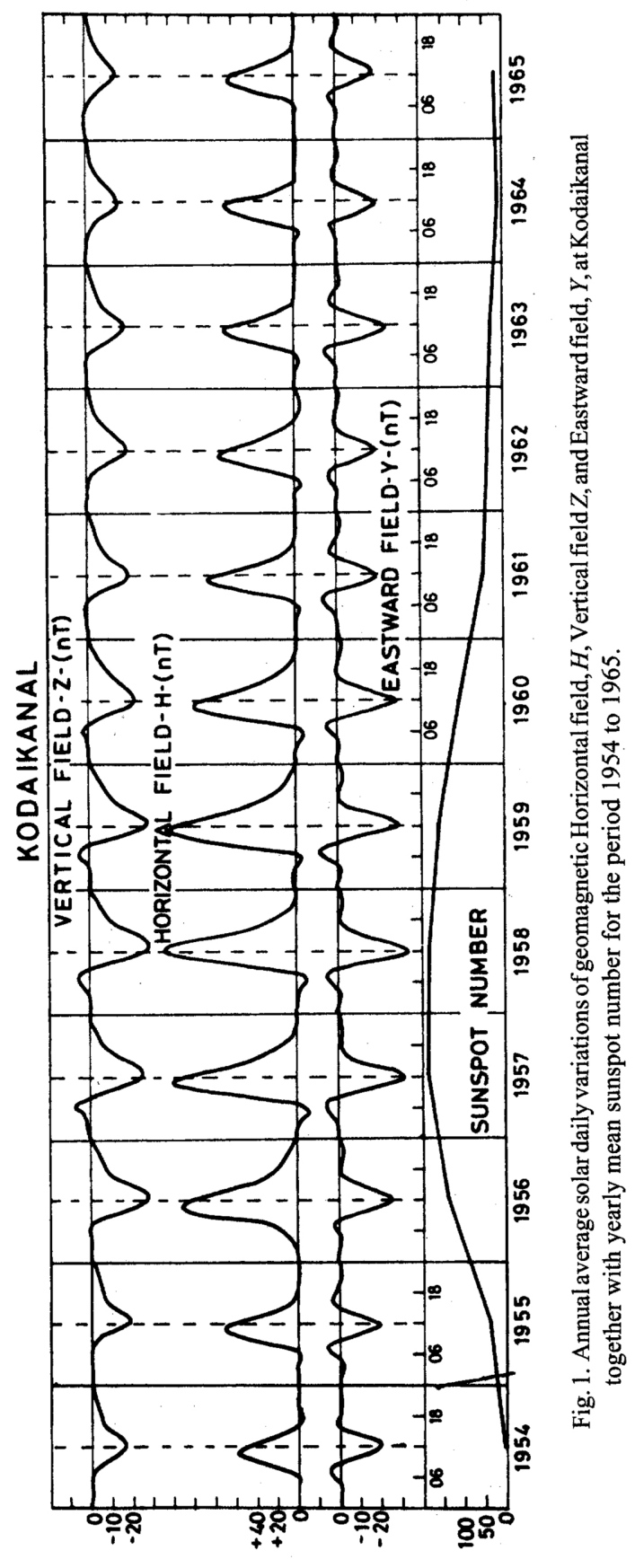




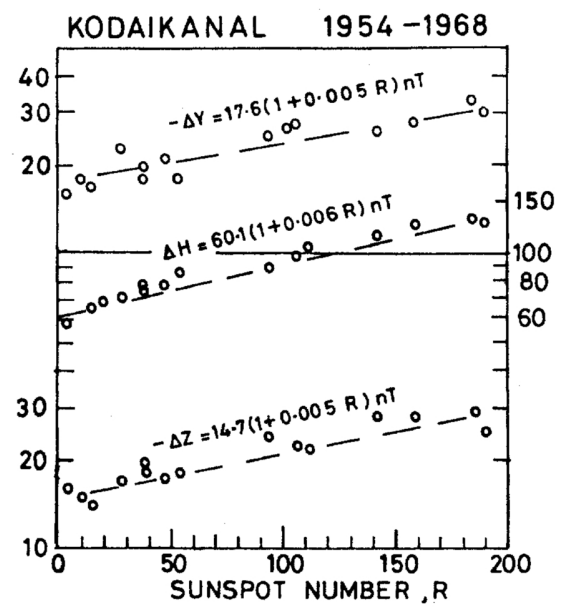

Fig. 2. The yearly mean midday values of $\Delta H, \Delta Z$ and $\Delta Y$ at noon at Kodaikanal plotted against yearly mean sunspot numbers for the period 1954-1968.

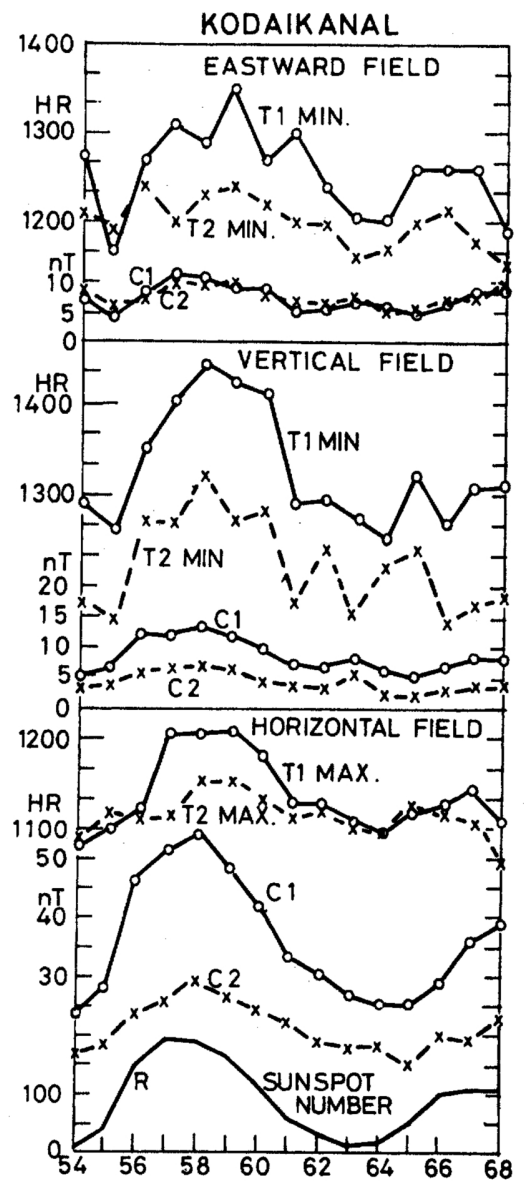

Fig. 3. The year to year progress of the diurnal and semi-diurnal components in the annual mean solar daily variations of horizontal, vertical and eastward field at Kodaikanal during the period 1954 to 1968. 
low and around $1300 \mathrm{LT}$ during high sunspot years.

It is thus concluded that the meridional currents at the equatorial latitudes in India form an important component of the equatorial electrojet current system the peak of which is advanced by one hour during the high sunspot years.

Next, we examine the solar daily variations of $H, Y$ and $Z$ fields at Kodaikanal during individual months. The period under study was divided into active sun years consisting of 1956 to 1959 and quiet sun years 1954-1955 and 1963-1966, the average sunspot number during these periods were 169 and 19 respectively. The monthly daily variations of $Y, H$ and $Z$ field during each of the months averaged over these two groups of years are shown in Fig. 4.

The features clear from these diagrams are that the daily variation of $H$ and $Z$ during any of the months are very similar to the annual average. The solar daily variation of eastward field showed large changes in its character with season, there was predominant seasonal variation in the amplitude of daily range. These curves were subjected to Fourier analysis and the amplitudes and phases of diurnal and semi-diurnal components were extracted. The month to month variations of these harmonics are shown in Fig. 5.

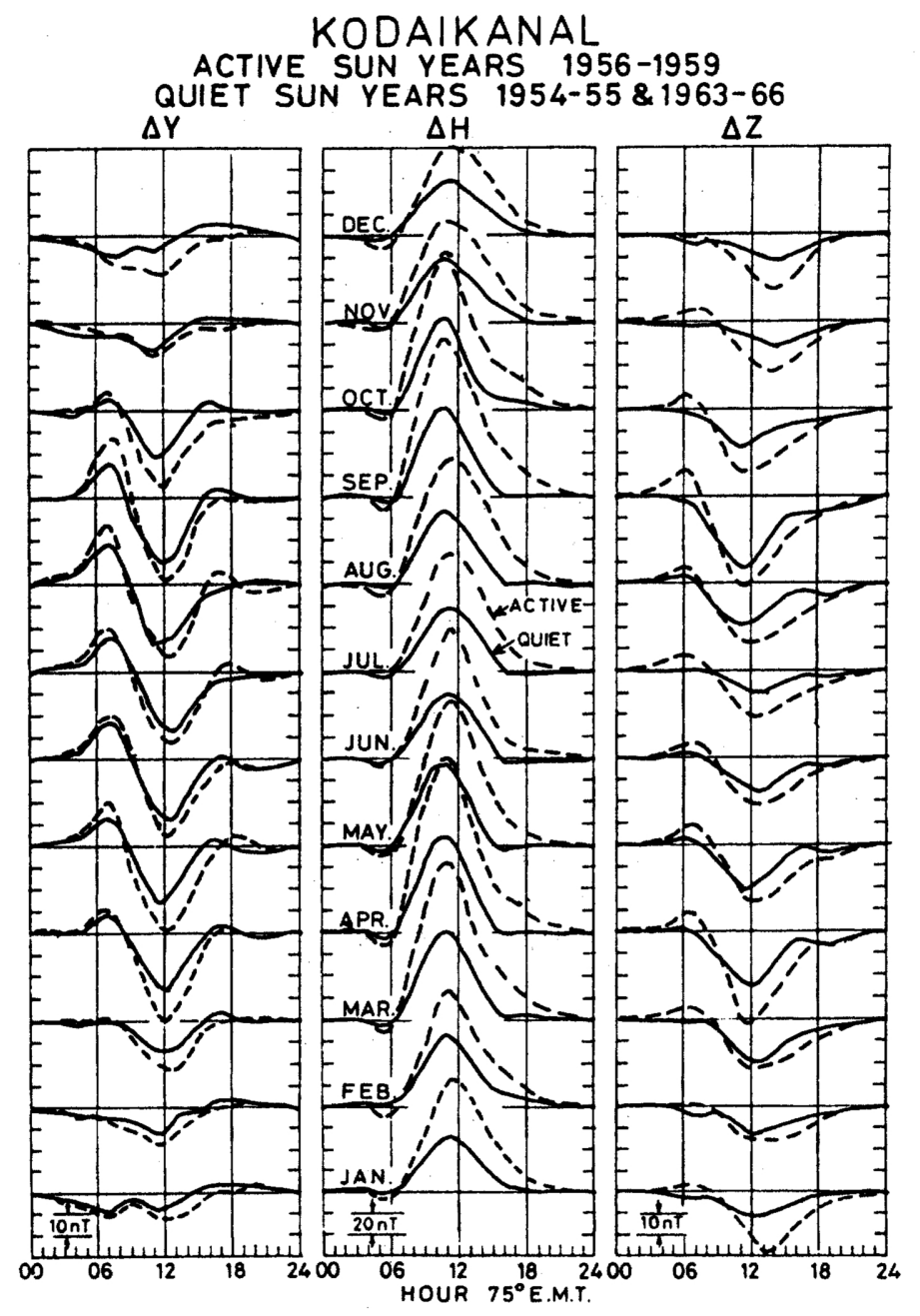

Fig. 4. Solar daily variations of eastward $(Y)$, horizontal $(H)$ and vertical $(Z)$ fields at Kodaikanal averaged for each month of quiet sum and active sum years. 
The amplitudes of diurnal $\left(C_{1}\right)$ and the semi-diurnal $\left(C_{2}\right)$ components in $H$ showed strong equinoctial maxima, the minimum during winter being deeper than the summer minimum. The amplitudes $C_{1}-Z$ and $C_{2}-Z$ also showed equinoctial maxima. The amplitudes $C_{1}-Y$ and $C_{2}-Y$ showed distinct annual wave with a maximum around summer months. Unlike $H$ and $Z$ fields, the eastward field showed stronger semidiurnal than the diurnal components. It thus seems that the variations of geomagnetic field at an equatorial station are the combined effects of equatorial electrojet current as well as of $S q$ current systems. The $H$ and $Z$ field are predominantly controlled by the electrojet current while the eastward field is controlled strongly by low latitude $S q$ current system.

The times of maximum excursions of diurnal as well as semi-diurnal components in the solar daily variation of $H$ field, $T_{1}(\max ) H$ and $T_{2}(\max ) H$ was restricted between 1100 and $1200 \mathrm{LT}$ for any of the months. $T_{1}(\max ) H$ was about 15-20 minutes later than corresponding $T_{2}(\max ) H$. Seasonally the maximum of $H$ occurred slightly later during local winter than summer.

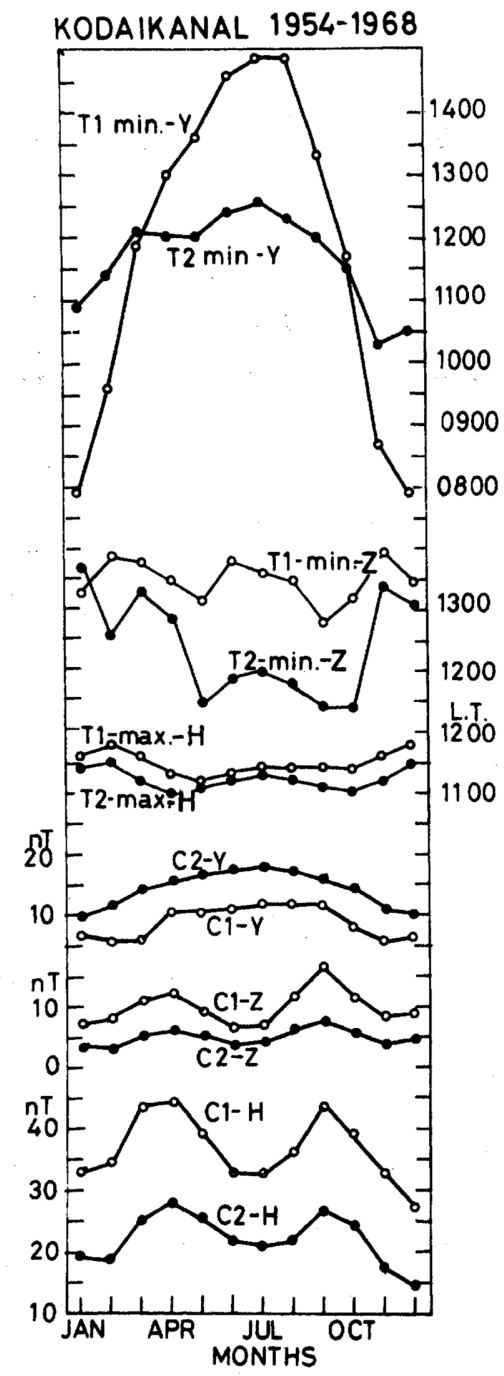

Fig. 5. Month to month variations of the amplitudes and phases of diurnal and semi-diurnal components of the solar daily variations of $H, Y$ and $Z$ fields at Kodaikanal averaged over the period 1954 to 1968 . 
Regarding the vertical field, the time of maximum of diurnal component $T_{1}$ (min) $Z$ did not show distinct seasonal effect but $T_{2}(\mathrm{~min}) Z$ occurred about one hour earlier during summer than in winter.

Very remarkable changes are seen in the seasonal variations of the times of diurnal and semi-diurnal components of the eastward field $T_{1}(\mathrm{~min}) Y$ and $T_{2}(\mathrm{~min}) Y$. Both the components occurred earliest during winter and gradually occurred later towards summer months. $T_{2}$ (min) $Y$ changed from 1030-1100 hr during December-January to $1230 \mathrm{hr}$ during June-July. The $T_{1}(\mathrm{~min}) Y$ was around $0800 \mathrm{LT}$ during December-January and changed to 1500 LT during July-August months. Thus, a change of seven hours in the phase of the diurnal components in $Y$ could change the character of daily variation with season.

The changes in amplitude and phase of diurnal and semi-diurnal components can be also shown in the harmonic dials (Fig. 6). It is to be noted that the phases in the harmonic dials indicate the times of maximum positive excursion. Concerning the harmonic dials for diurnal ( 24 hourly) component, it is seen that the $H$ field was roughly in phase opposition with $Z$ and $Y$ fields. The times of maximum excursion of $H$ were between 11-12 hours and of $Z$ between 01-02 hr. The phase of maximum $Y$ varied from $1900 \mathrm{LT}$ to $0300 \mathrm{LT}$. The semi-diurnal component of $H$ was again in phase opposition with those of $Z$ and $Y$ field. In case of $H$ field the amplitude changed significantly with season but the phase was practically constant. In contrast the phase of $Y$ field changed with season with relatively smaller changes in amplitude.

Next, the values of midday $\Delta H$ and $\Delta Y$ during individual quiet days $(A p<10)$ of the winter months of 1964-1965 were selected and the monthly means were subtracted to remove any month to month variations. The resultant deviations in $\Delta Y$ were plotted against corresponding deviations of $\Delta H$ as in Fig. 7. In spite of some scatter of points it can be safely concluded that the day to day variations in $\Delta Y$ is related to corresponding variations in $\Delta H$. An increase of $\Delta H$ (electrojet current) is associated with an increase

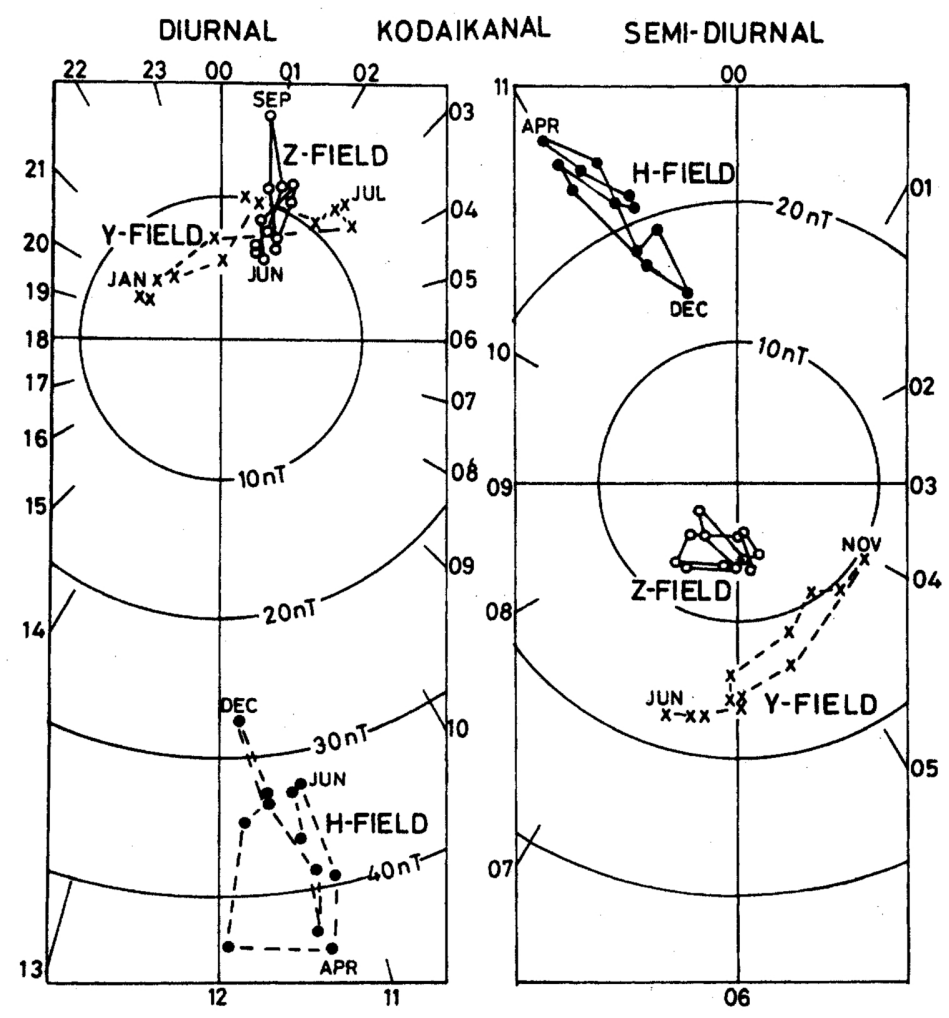

Fig. 6. Harmonic dials showing the amplitudes and phases of maximum positive deviations of the diurnal and semi-diurnal components of solar daily variations of $H, Y$ and $Z$ fields at Kodaikanal averaged over the period 1954-1968. 
of westward field.

To test whether the abnormal daily and seasonal variations of the eastward field at Kodaikanal is due to some restricted anomaly or is a part of general current system of a larger regional extent. In Fig. 8 are shown yearly mean daily variations of $H, Z$ and $Y$ components of the geomagnetic field at all geomagnetic observatories operating in India during the period under study. $\Delta H$ at any of these observatories showed typical maxima just before noon with amplitudes being $102 \mathrm{nT}$ at Trivandrum (TRD), $95 \mathrm{nT}$ at Kodaikanal (KOD), $79 \mathrm{nT}$ at Annamalainagar (ANN) and $48 \mathrm{nT}$ at Alibag (ABG). The variations of $\triangle Z$ at TRD showed a maximum around $1000 \mathrm{hr}$ and a minimum around $1600 \mathrm{hr}$ roughly in coincidence with the temporal rate of the changing of $\Delta H$. This feature of $Z$ component at TRD has been attributed to the abnormal oceanic and induction effects (SRIVASTAVA and SANKAR NARAIN 1970; RAJARAM et al., 1979).

The variations of $\triangle Z$ at KOD and $A N N$ show a prominent minimum around noon, the amplitude being larger at ANN than at KOD suggesting the effect of the electrojet band currents, ANN being at the fringe of electrojet belt experiences largest value of $\Delta Z$. The variation of $\Delta Z$ at $\mathrm{ABG}$ is typical of a low latitude station outside the equatorial electrojet belt.

The $\Delta Y$ at any of the three electrojet observatories (TRD, KOD and ANN) shows a prominent minimum around noon, the daily variation is $\Delta Y$ is almost reverse to the daily variation of $\Delta H$. The $\Delta Y$ at ABG showed a maximum around $0900 \mathrm{hr}$ and a minimum around 1300-1400 hr, typical of a low latitude station primarily under the influence of global $S q$ currents.

It is suggested that in the Indian longitude sector the variations of eastward field is the result of both $S q$ currents at low latitudes and a meridional current at equatorial latitudes.

To test the relationship of abnormal seasonal effects of the daily variations of the eastward field $(Y)$ at Kodaikanal with similar variations at other stations in India, in Fig. 9 are shown the daily variations of the eastward field at TRD, KOD, ANN, and ABG averaged for months (Nov., Dec., Jan. and Feb.). E months (Mar., Apr., Sept., and Oct.) and J months (May, June, July and Aug.) of the years 1958-1965. The largest amplitudes of daily variation occur during J months at any of the stations, with a positive peak around $0800-0900 \mathrm{hr}$ and a minimum around 1300-1400 $\mathrm{hr}$. The range of variations increases with latitude of the station. During the $\mathrm{E}$ months, the variation is similar to that in $\mathrm{J}$ months with reduced amplitudes of forenoon as well as afternoon peaks. During D-months the daily variation is reversed at any of the stations in Indian longitude sector.

It is thus confirmed that the abnormal seasonal effects in the daily variation of the eastward magnetic field at Kodaikanal is a component of general current system in the Indian longitude sector.

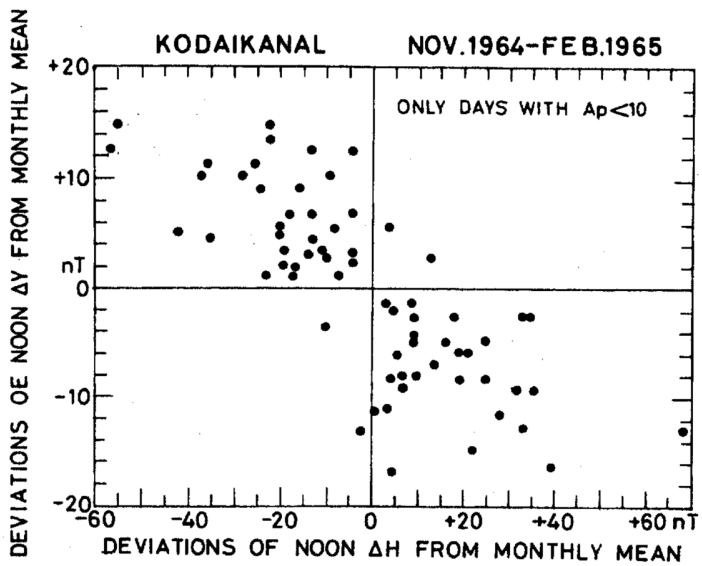

Fig. 7. Mass plots of the deviations of $\Delta Y$ from its monthly mean plotted against corresponding deviations of $\Delta H$ at Kodaikanal for the winter months of 1964-65. 


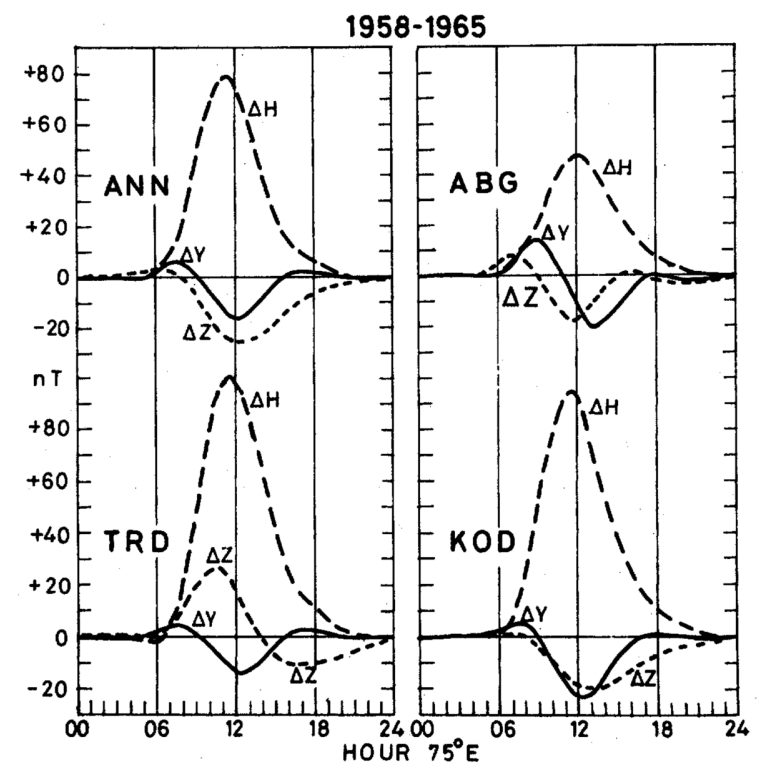

Fig. 8. Yearly daily variations of $H, Y$ and $Z$ components of geomagnetic field at Trivandrum (TRD), Kodaikanal (KOD), Annamalainagar (ANN) and Alibag (ABG) averaged over the period 1958-1965.

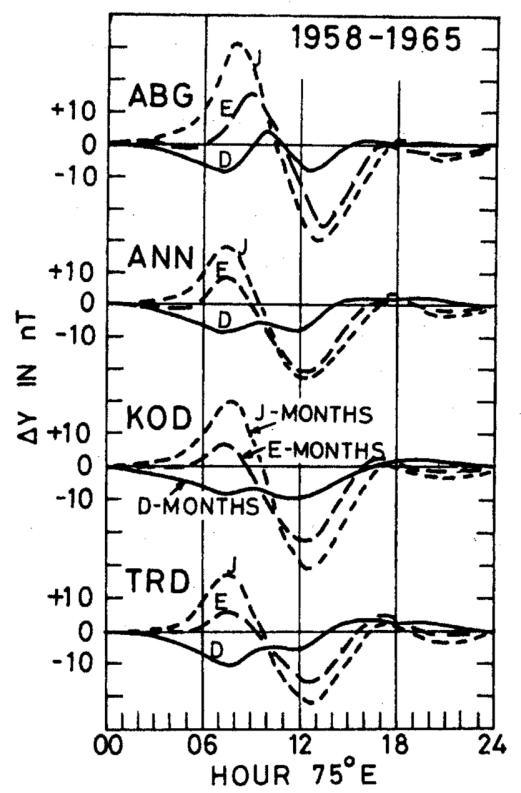

Fig. 9. Seasonal daily variations of eastward $(Y)$ geomagnetic field at Trivandrum (TRD), Kodaikanal (KOD) Annamalainagar (ANN) and Alibag (ABG) averaged over the period 1958-1965.

\section{Discussions}

HIRONO (1952) and BAKER and MARTYN (1953) had suggested the modifications of the electrical conductivities in the $E$ region over the magnetic equator due to the inhibition of a vertical Hall polarization 
field. SUGIURA and CAIN (1966) gave the first numerical model of the equatorial electrojet using the results of BAKER and MARTYN (1953). UNTIEDT (1967) obtained a solution satisfying $\nabla \cdot J=0$ condition which necessitated the presence of vertical currents. This requires the presence of meridional currents described by (1) an upward current at the equator possibly going upto the $F$ region, (2) a downward flow of the current along field lines, (3) a return current towards the dip equator in the $E$ region. Because the toroidal field is confined in the $E$ and $F$ regions, it is not supposed to be detected at ground level. With rocket-borne magnetometers, MUSSMAN and SEILER (1978) have detected deviations in the model magnetic field variations due to meridional current, near the noon meridian of the coast at Natal, Brazil.

MAEDA et al. (1982) detected systematic change in the $D$ component near the duskside of the dip equator from the analysis of MAGSAT data. Later analyses of $\Delta H, \Delta D, \Delta Z$ and $\Delta F$ at low latitudes during MAGSAT data, MAEDA et al. (1985) found that (1) $\Delta H$ generally shows negative values larger at dusk than at dawn and is in good correlation with $D s t$ index on both dawnside and duskside. (2) $\Delta D$ shows a distinct variation near the dip equator only on the duskside with a small shift of the baseline. A negative peak is seen near $8^{\circ} \mathrm{N}$ and a positive peak near $8^{\circ} \mathrm{S}$ dip latitude. The amplitude is larger in the South American zone than in the Indian zone and on altitude such that it is larger at lower altitudes. It is also positively correlated with sunspot number. (3) $\Delta Z$ shows a general tendency of being positive in the northern hemisphere and negative in the southern hemisphere.

MAEDA et al. (1985) attributed the distinct variation of $\triangle D$ across the equator to be due to a meridional current system in the ionosphere. TAKEDA and MAEDA (1983) have suggested the effects of the $F$-region dynamo to explain the anomalous variations of $D$ component. They showed that the meridional current caused by neutral pressure gradients can well reproduce this event including the dependence on solar activity. MAEDA et al. (1985) had suggested the trans-equatorial field-aligned currents in the dawn and dusk periods to explain the shifts in the base line of $\Delta D$ at the equator. Further, the negative shifts of $\Delta H$ and $\Delta F$ and the latitudinal gradients in $\Delta Z$ were suggested to be the effects of westward ring currents.

Thus a complex combination of the ionospheric, $E$ and $F$ region currents as well as the magnetospheric current are suggested as the cause of observed variations of magnetic field components by the MAGSAT.

During the midday hours the role of magnetospheric currents would be relatively smaller than that of ionospheric currents on the magnetic field variations at equatorial latitudes on geomagnetically quiet day.

The present results indicate prominent role of meridional currents at low latitudes in understanding the daily variations of the eastward magnetic field at equatorial latitudes. The correlation of the day to day changes between eastward and northward fields at Kodaikanal indicate a close relationship between the meridional and eastward currents over the dip equator. Thus the global $S q$ and the electrojet currents are in a way linked with each other. Distinct transequatorial currents during midday hours and the abnormal seasonal effects on the eastward geomagnetic field does indicate that the low latitude dynamo field is generated by different tidal modes during very different seasonal dependence. An asymmetric semidiurnal mode with changing phase with season could explain the observed variations of the $D$ component of the geomagnetic field at Kodaikanal.

STENING (1977) calculated the field aligned currents generated by " $1,-2$ " mode wind system and found a band of intense low latitude currents which contribute substantially to the eastward daily magnetic variation of $\Delta Y$.

Many workers studied the field aligned currents generated by the asymmetric dynamo action in the northern and southern hemispheres. MAEDA (1974) found field aligned currents flowing mainly in the daytime from the winter to the summer hemispheres. FUKUSHIMA (1979) used an alternative method for calculation of electric charge distribution in the ionosphere associated with the dynamo action for any given air motion and found that if dynamo action is asymmetric in the northern and southern hemispheres, then the potential difference between the north and south conjugate pair of stations will trigger the field aligned currents flowing the winterside to the summerside in the daytime. TAKEDA (1990) suggested that under solstitial conditions there are two current systems associated with field aligned currents. One is the 
current flowing from the summer to winter hemisphere around the center of the ionospheric current vortex. The other is from the winter to the summer hemisphere in the morning and vice versa in the afternoon.

In conclusion, I agree with the suggestion of Fukushima that a concentrated study of $D$-component of the geomagnetic field at low latitude is very necessary to understand the equatorial electrojet itself.

Thanks are due to Director General, Council of Scientific and Industrial Research, New Delhi and to Director, Physical Research Laboratory, Ahmedabad for facilities provided to the author for the research work. Thanks are also due to Prof. N. Fukushima for useful discussions and suggestions and to one of the referee for some suggestions in the manuscript that has improved the presentation.

\section{REFERENCES}

ARORA, B. R., D. R. K. RAO, and N. S. SASTRI, Latitudinal variation of geomagnetic solar and lunar tides in the Indian region, Proc. Ind. Acad. Sci. (Earth and Planet. Sci.), 89(3), 333-346, 1980.

BAKer, W. G. and D. F. MARTyn, Electric currents in the ionosphere 1. The conductivity, Phil. Trans. Roy. Soc. Lond., A246, 281-294, 1953.

EgEDAL, J., The magnetic diurnal variation of the horizontal force near the magnetic equator, Terr. Magn. Atmos. Electr., 52, 449451, 1947.

FUKUSHIMA, N., Electric potential difference between conjugate points in the middle latitudes caused by asymmetric dynamo in the ionosphere, J. Geomag. Geoelectr., 31, 401-409, 1979.

Fukushima, N., Transequatorial field-aligned currents at low latitudes and their possible connections with the equatorial electrojet, Paper submitted at the IEEY Workshop at Sao Jos dos Campos, Brazil, October, 1992.

GuPtA, J. C., On solar and lunar equatorial electrojets, Ann. Geophys., 29, 49-60, 1973.

HIRONo, M., A theory of diurnal magnetic variations of equatorial regions and conductivity of the ionospheric $E$ region, $J$. Geomag. Geoelectr., 4, 7-21, 1952.

HutTon, R., $S q$ currents in American equatorial zone during the IGY-1 seasonal effects, II Day-to-day variability, J. Atmos. Terr. Phys., 29, 1411-1427, 1967.

MAEDA, H., Field aligned currents induced by asymmetric dynamo action in the ionosphere, J. Atmos. Terr. Phys., 36, 1395-1401, 1974.

MAEDA, H., T. IYEMORI, T. ARAKI, and T. KAMEI, New evidence of a meridional current system in the equatorial ionosphere, Geophys. Res. Lett., 9, 337-340, 1982.

MAEDA, H., T. KAMEI, T. IYEMORI, and T. ARAKI, Geomagnetic perturbations at low latitudes observed by Magsat, J. Geophys. Res., 90, 2481-2486, 1985.

Mussman, G. and E. SeILER, Detection of meridional currents in the equatorial ionosphere, J. Geophys., 44, 357-372, 1978.

PATIL, A., B. R. ARORA, and R. G. RASTOGI, Daily variation of geomagnetic field near the focus of $S q$ current system in Indian longitude, Proc. Ind. Acad. Sci. (Earth Planet. Sci.), 92, 239-245, 1983.

Price, A. T. and D. J. Stone, The quiet day magnetic variations during the IGY, Ann. IGY, 35, 63-269, 1964.

RAJARAM, M., B. P. Singh, and A. K. Agarwal, Effect of the presence of a conducting channel between India and Sri Lanka on the features of equatorial electrojet, Geophys. J. R. Astron. Soc., 56, 127-138, 1979.

RASTOGI, R. G., Disintegration of ionospheric Sq loop current system during winter solstices along $75^{\circ} \mathrm{E}$ longitude, Ann. Geophys., 11, 40-46, 1993a.

RASTOGi, R. G., Complexities of ionospheric current system at low latitudes, Ann. Geophys., 1993b (in press).

RASTOGI, R. G. and K. N. IYER, Quiet day variation of geomagnetic $H$ field at low latitudes, J. Geomag. Geoelectr., 28, 461-479, 1976.

Rastogi, R. G. and A. Patil, On certain aspects of daily variations of geomagnetic field at low latitudes, J. Geomag. Geoelectr., 44, 495-503, 1992.

Singh, B. P., A. K. Agarwala, and L. Carlo, Anomalies in $H$ at Indian equatorial stations and their effect on equatorial enhancement, J. Atmos. Terr. Phys., 44, 241-244, 1982.

SRIVASTAVA, B. J. and P. V. SANKAR NARAIN, Anomalous geomagnetic variations in the penensular India-ocean effect and upper mantle conductivity structure, Bull. NGRI, 8, 125-134, 1970 .

Stening, R. J., Field aligned currents driven by the ionospheric dynamo, J. Atmos. Terr. Phys., 39, 933-937, 1977.

Sugiura, M. and J. C. CAIn, A model equatorial electrojet, J. Geophys. Res., 71, 1869-1877, 1966.

SugIURA, M. and D. J. Poros, An improved model equatorial electrojet with a meridional current system, J. Geophys. Res., 74, 4025-4034, 1969.

TAKEDA, M., Geomagnetic field variation and the equivalent current system generated by an ionospheric dynamo at the solstice, 
J. Atmos. Terr. Phys., 52, 59-67, 1990.

TAKEDA, M. and H. MAEDA, $F$ region dynamo in the evening-Interpretation of equatorial $\triangle D$ anomaly found by MAGSAT, $J$. Atmos. Terr. Phys., 45, 401-408, 1983.

UnTIEDT, J., A model of equatorial electrojet involving meridional currents, J. Geophys. Res., 72, 5799-5810, 1967. 